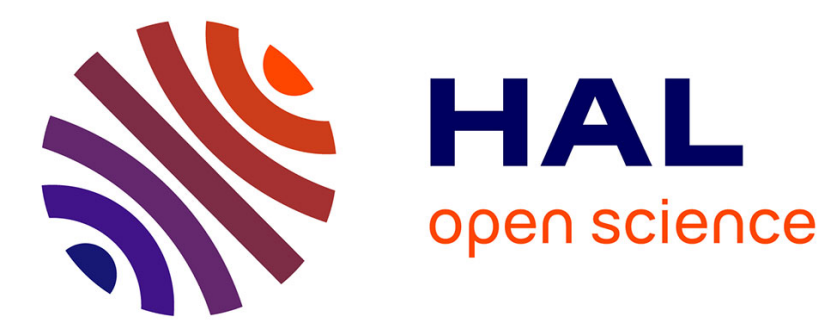

\title{
UHF Near-Field Wireless RFID Power Transfer Through Two Distant Rectangular Waveguides
}

I. Rakotomalala, Pierre Lemaitre-Auger, S. Tedjini

\section{To cite this version:}

I. Rakotomalala, Pierre Lemaitre-Auger, S. Tedjini. UHF Near-Field Wireless RFID Power Transfer Through Two Distant Rectangular Waveguides. 2019 49th European Microwave Conference (EuMC), Oct 2019, Paris, France. pp.547-550, 10.23919/EuMC.2019.8910771 . hal-02388099

\section{HAL Id: hal-02388099 \\ https://hal.univ-grenoble-alpes.fr/hal-02388099}

Submitted on 1 Dec 2019

HAL is a multi-disciplinary open access archive for the deposit and dissemination of scientific research documents, whether they are published or not. The documents may come from teaching and research institutions in France or abroad, or from public or private research centers.
L'archive ouverte pluridisciplinaire HAL, est destinée au dépôt et à la diffusion de documents scientifiques de niveau recherche, publiés ou non, émanant des établissements d'enseignement et de recherche français ou étrangers, des laboratoires publics ou privés. 


\title{
UHF Near-Field Wireless RFID Power Transfer Through Two Distant Rectangular Waveguides
}

\author{
I. Rakotomalala, P. Lemaitre-Auger, S. Tedjini \\ Grenoble-inp/LCIS University Grenoble Alpes Valence, France \\ \{ imbolatiana.rakotomalala, pierre.lemaitre-auger, smail.tedjini \}@lcis.grenoble-inp.fr
}

\begin{abstract}
Feasibility of a wireless power transfer (WPT) system for supplying power to a metallically closed volume is demonstrated. The solution proposed is based on a metallic rectangular waveguide. After optimization, simulated transmission coefficient is $-1 \mathrm{~dB}$, corresponding to power transmission efficiency of $\mathbf{8 0} \%$. This near-field WPT system is a good candidate for several specific RFID UHF applications where the measuring volume is mobile with respect to the base station.
\end{abstract}

Keywords - near-field, relay antenna, RFID, rectangular waveguide, wireless power transfer

\section{INTRODUCTION}

Passive radiofrequency identification (RFID) is a well know technique nowadays. It has become progressively popular in automatic identification data collection systems. It allows wireless transfer and the collect of information about goods and products, animals, people [1]. Usually, an RFID system is composed of RFID readers and RFID tags. The latter are attached to every object to be identified, and transmits a unique identification code, and the RFID reader reads and writes the identification codes stored by the RFID tag [2]. The operating frequency ranges cover from Low Frequency (LF) to Ultra High Frequency (UHF) bands, depending on the purpose of the system, and the communication ranges, and according standards of legislation the maximum effective isotropic radiated power (EIRP) is limited to $35 \mathrm{dBm}$ [3] for the European region.

Naturally, for such cases of use to work, a complete RFID system has to be located inside the closed volume [4] . Or at least antennas must be located inside the closed volume and be connected with coaxial cables to an external RFID reader located outside of it [5]. In both cases, the system can be made mobile with the use of batteries, but it will require to be connected to an external power source from time to time. And an RFID reader is required per closed volume.

In some situations, it would be interesting to have mobile and at the same time completely passive mobile closed volumes, eliminating all environmental problems created by batteries [6][7] . To do this, a system includes a local RFID reader with several antennas installed inside the enclosure. The system establishes communication between a local RFID reader and a central station with protocols such as Bluetooth or Zigbee there are several patents related to that idea. Three of them present the details of a system for tracking and monitoring an inventory within one or several confined metallic enclosure [5], [8]-[10]. However, in this system, only information is transmitted through the confined metallic enclosure, the power required by the RFID reader is contained inside the enclosure.

In addition to the previous requirement, sharing the same RFID reader for several mobile closed volumes would be a great economical advantage. An example of a scenario could be several work shop trolleys containing tools used in an aeronautic industry, aero spatial industry or a nuclear plant. A single RFID reader could be placed on a fixed station and to realize the inventory of the tools inside a trolley, an operator would simply have to punch the trolley next to the fixed station. This requires the need of a wireless power transmission of the interrogating RFID signal and the retro diffused responses of the tags inside the trolley.

In this work, we propose and study such a wireless power transfer (WPT) system. It is composed of two separate rectangular waveguides. The WPT system is equivalent to a waveguide discontinuity, namely, an open one which is describe in [11]-[14]. These study analyze the behavior of an open-ended discontinuity of a rectangular waveguide as a radiating element from a computational point of view, without taking into account possible applications.

In Section II, the whole structure and the optimization of the design of the WPT system is presented with numerical simulations. In Section III, experimental results are presented to validate the concept

\section{SySTEM DESIGN}

\section{A. Waveguide antenna design}

The whole system consists in a mobile metallic cabinet and a fixed station. The later contains the RFID reader connected to the WPT system. The former contains all tag items and at least one inner antenna connected to the WPT system, as it is shown in Fig.1. The WPT system is two rectangular waveguides connected to a coaxial cable on one side and open in air on the other side. The separation between the two openings and proper alignment can easily be assured by an appropriate mechanical system. 


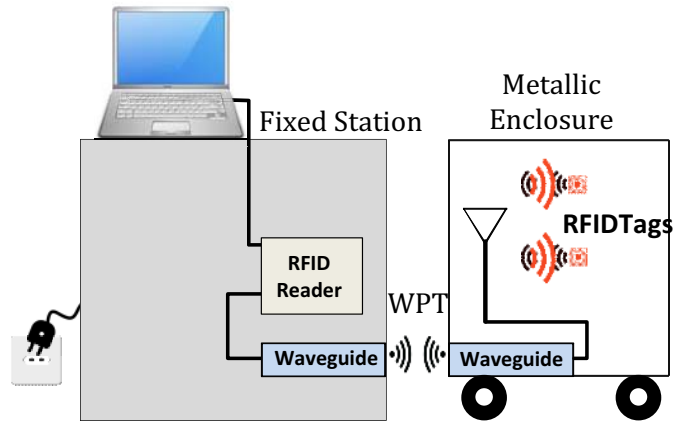

Fig. 1. Reading RFID tag with WPT system

\section{B. Waveguide Design}

Waveguide are commonly used in a variety of application in the microwave frequency band, especially in the range of centimeter and millimeter waves, mostly because they are relatively low loss and have a large power-handling capability. The solution uses such waveguides, as depicted in Fig. 2. The WPT system is equivalent to a waveguide discontinuity, namely, an open one. Therefore, when the electromagnetic field impinges on the termination of the transmitting waveguide, part of the associated power is coupled to the second waveguide, while a second part is reflected, and a third part is radiated in free space.

There is a standard rectangular waveguide which covers the concerned frequency band: the European Telecommunication Institute (ETSI) frequency band, 866 to $868 \mathrm{MHz}$. It is the WR1150 waveguide, with a broad wall width, $W$, of 291.1 $\mathrm{mm}$, a height, $H$, of $146.05 \mathrm{~mm}$, and a cutoff frequency at 513 $\mathrm{MHz}$. These dimensions are still very large, especially when it is necessary to use more than one WPT system, depending on the number of inner antennas. It is necessary to resize the waveguides, not only to get less bulky solution, but also a lighter solution. So, according to [15], it is possible to estimate the dimensions of the waveguide especially the broad wall width:

$$
W=\frac{C}{2 f_{c}}
$$

where $c$ is the speed of light, and $f_{c}$ is the cutoff frequency.

With the $W$ obtain as a starting point for one waveguide. Numerical optimization is done to minimize the reflected and radiated power losses by considering the two waveguides with Ansys HFSS.

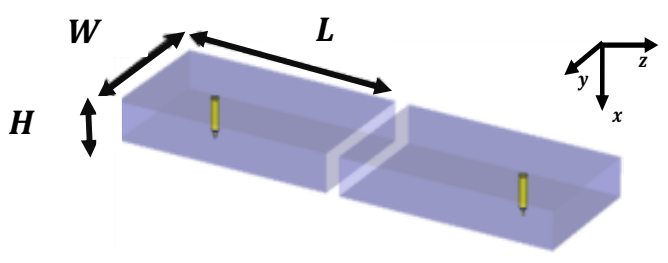

Fig. 2 Design of the straight waveguide WPT system
A cutoff frequency less than $860 \mathrm{MHz}$ was found. $W$ equal to $174.8 \mathrm{~mm}, H$ equal to $40 \mathrm{~mm}$, and a length, $L$, of $305 \mathrm{~mm}$, as presented in Fig. 2, gave the best results. Both transmitting and receiving waveguides are well impedance-matched with the feeding circuit and the load impedance, respectively. A reflection loss of $-19 \mathrm{~dB}$, and a minimal insertion loss of $-1.02 \mathrm{~dB}$ are achieved at $868 \mathrm{MHz}$, when they are face-toface and separated by an air gap of $2 \mathrm{~cm}$. Results show that the system operates from $864 \mathrm{MHz}$ to $870 \mathrm{MHz}$, as shown in Fig. 3 , which is compatible with the ETSI UHF RFID band.

From the $S$-parameters, the power transfer efficiency, $\eta$, can be computed the following way[16]:

$$
\eta=\frac{P_{R x}}{\mathrm{P}_{\mathrm{av}}}=\frac{\left|S_{21}\right|^{2}\left(1-\left|\Gamma_{R x}\right|^{2}\right)}{\left|1-S_{22} \Gamma_{R x}\right|^{2}\left(1-\left|\Gamma_{T x}\right|^{2}\right)}
$$

where $P_{R x}$ is the power delivered to the receiving port and $P_{a v}$ is the available power from the excitation port, $\Gamma_{R x}$ and $\Gamma_{T x}$ are the reflection coefficients at the receiving and excitation ports respectively. They are expressed as [15]:

$$
\Gamma_{T x}=\mathrm{S}_{11}+\frac{S_{12} S_{21} \Gamma_{R x}}{1-S_{22} \Gamma_{R x}} \quad \Gamma_{R x}=\mathrm{S}_{22}+\frac{S_{12} S_{21} \Gamma_{T x}}{1-S_{11} \Gamma_{T x}}
$$

The power transfer efficiency is higher than $80 \%$ over all the band, the maximum value is $85 \%$.

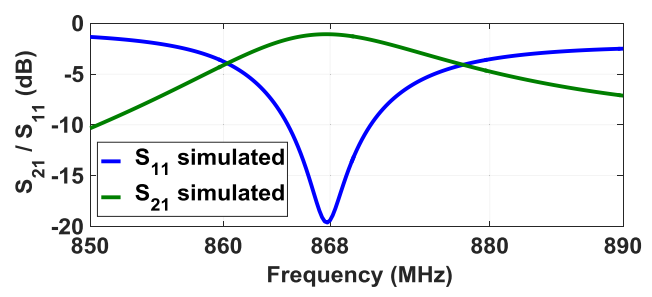

(a)

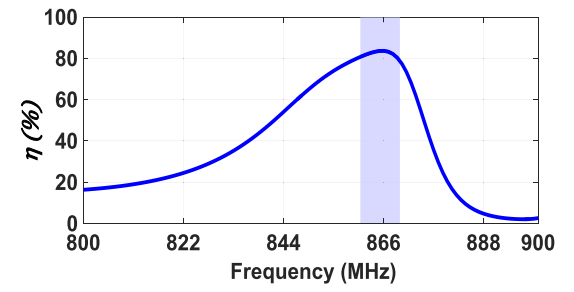

(b)

Fig. 3 Performances of waveguide system: (a) S-parameters, (b) PTE

\section{Tolerance estimation}

The tolerances of the system were evaluated in order to validate the feasibility of a real implementation. For that, the frequency was fixed to $868 \mathrm{MHz}$, and the parameter $S_{21}$ was simulated while one side of the WPT system was displaced. along $z, y$, and $x$ axis.

The threshold limit was fixed to $-3 \mathrm{~dB}$ where half of injected power should be received by the second waveguide. As depicted in Fig. 4 a tolerance of $2.8 \mathrm{~cm}$ is obtained along the $x$-axis while more than $5 \mathrm{~cm}$ is obtained for $y$ and $z$ axes. 


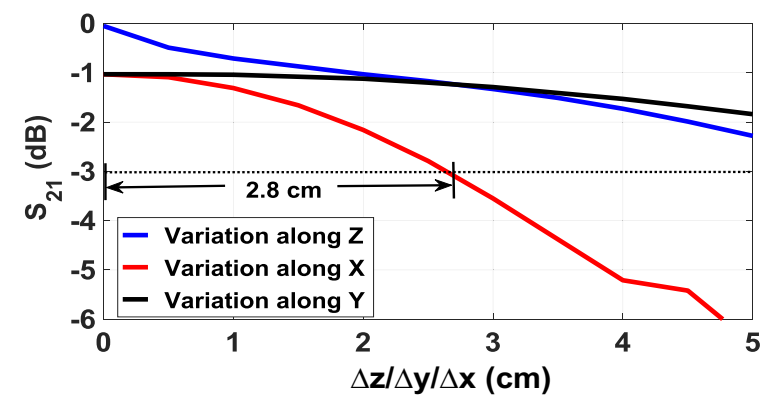

Fig. $4 S_{21}$ variation at $868 \mathrm{MHz}$. Along the $\mathrm{x}$, y and z-axis

\section{EXPERIMENTAL VALIDATION}

In order to validate the efficiency of the proposed solution, measurements were made. But because of available components in our laboratory, a standard rectangular waveguide, WR430, was used instead of the optimized one. It worth mentioning here that the waveguide band is out of the target one in UHF RFID but measurements of the $S$ parameters can still be done, as well as the calculation of the power transfer efficiency. The response of the WR430 waveguide was simulated so it can be compared to the measurements. The dimensions and the photography of the WR430-based-system are shown in Fig. 5.

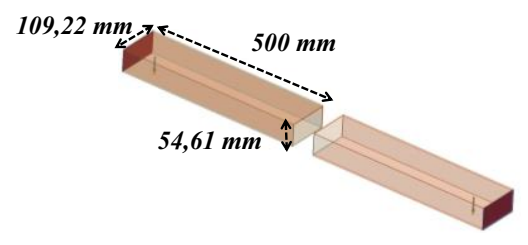

(a)

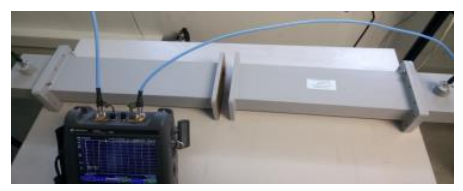

(b)

Fig. 5 Design of the standard straight waveguide WPT (WR430) for WPT system

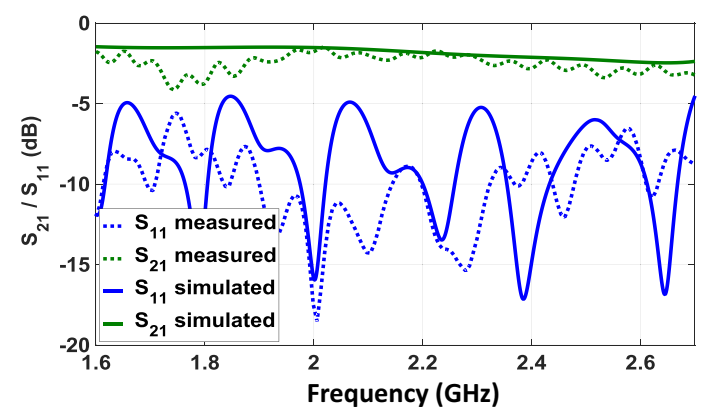

Fig. 6 Measured and simulated S-parameters and efficiency with the standard straight waveguide, W430 Top) S-parameters. Bottom) Power transfer efficiency.
Measured and simulated S-parameters of the WPT system are presented in Fig. 6. The agreement between simulation and measurements is fair, and validates the feasibility of this solution. The power transfer efficiency is also presented in Fig. 7. Best results of $85 \%$ are obtained at $2.45 \mathrm{GHz}$.

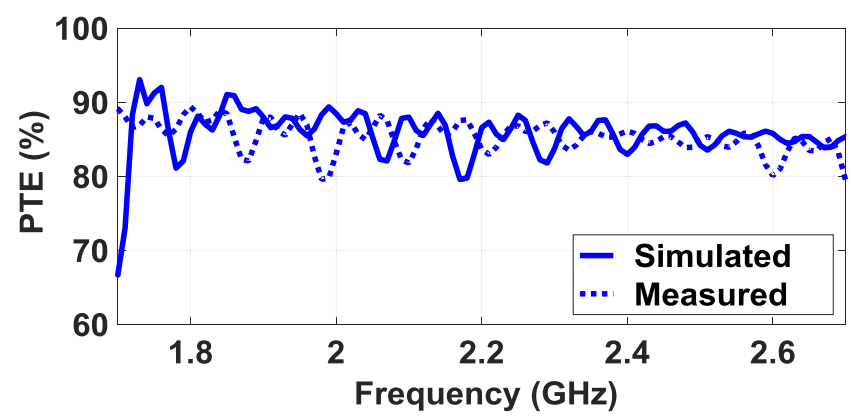

Fig. 7 PTE of the rectangular waveguide WR 430

A tolerance study was also done, but since this structure does not operate at the desired frequency, we arbitrarily evaluated the tolerance at $2.45 \mathrm{GHz}$ as depicted in Fig. 8

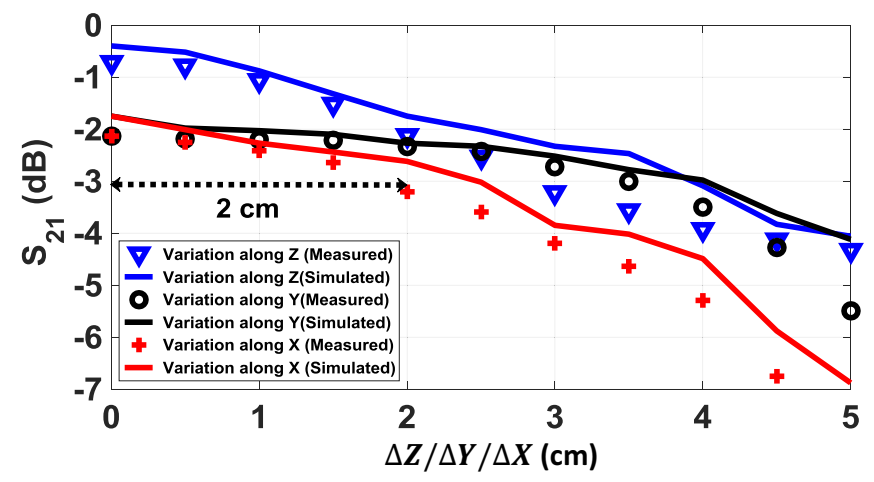

Fig. $8 S_{2 I}$ variation at $2.45 \mathrm{GHz}$. Along the $\mathrm{x}$, y and $\mathrm{z}$-axis

The results can be observed in Fig. 8. Regarding the longitudinal distance between the receiving and transmitting parts of the WPT system, a stable an optimal distance is found between $0 \mathrm{~cm}$ to $1 \mathrm{~cm}$ air gap. For smaller gaps or bigger ones, insertion loss increases. This is caused by mismatch of the whole structure. For an arbitrary value of $-3 \mathrm{~dB}$ of the $S_{21}$, a tolerance of $2.5 \mathrm{~cm}$ is obtained along the $z$-axis. Concerning height (along the $x$-axis) or lateral (along the $y$-axis) misalignments, at $-3 \mathrm{~dB}$, tolerances of $2 \mathrm{~cm}$ and $2.5 \mathrm{~cm}$ were respectively obtained.

\section{CONCLUSION}

This paper demonstrated the feasibility of WPT system for UHF applications for RFID applications. The solution is based on metallic waveguides placed face to face. A power tranfert efficiency of $80 \%$ and acceptable tolerances to misalignement were obtained. The proposed solution has very satisfactory performance in terms of efficiency, it is robust and well adapted for transmitting power between two seperated elements of an RFID system. 


\section{REFERENCES}

[1] K. Finkenzeller, RFID Handbook. Chichester, UK: John Wiley \& Sons, Ltd., 2003

[2] En ultra et super hautes fréquences UHF-SHF Théorie et mise en oeuvre, DUNOD. L'USINE NOUVELLE, 2008.

[3] (2014) "ETSI TR 102436 V2.1.1,". [Online]. Available: http://www.etsi.org.

[4] Michael D. Westrick; Daniel L. Sands, "RF passive repeater for metal container," US 8,462,062 B2, 2013

[5] N. Venkata Kodukula, "Method and system for reading objects having radio frequency identification (RFID) tags inside enclosures," US 2007/0001809 A1, 2007

[6] T. Moura, N. B. De Carvalho, P. Pinho, and A. C. S. Diodes, "Design of an Efficient D-TV Energy Harvesting System for Low-power Applications," 2015 IEEE 15th Mediterr. Microw. Symp., pp. 1-4, 2015

[7] U. De Aveiro, "Backscatter Wireless Sensor Network with WPT Capabilities," pp. 6-9, 2015

[8] S. Sabesan, M. Crisp, R. V. Penty, and I. H. White, "Passive UHF RFID interrogation system using wireless RFID repeater nodes," 2013 IEEE Int. Conf. RFID, RFID 2013, pp. 136-143, 2013.

[9] John R. Tuttle, "Electronic monitoring systems, shipment container monitoring systems and methods of monitoring a shipment in a container," US 8,665,072 B2, 2014.

[10] Patricia Denise Mackenzie; Judith Ann Guzzo; Joseph James Salvo, "System and method for monitoring and tracking invetories," US 2009/0160646 A1, 2009.

[11] M. Guglielmi, G. Gheri, M. Calamia, G. Pelosi, and S. Member, "Rigorous Multimode Network Numerical Representation of Inductive Step," IEEE Trans. Microw. Theory Tech., vol. 42, no. 2, pp. 317-326, 1994.

[12] A. Chakraborty, "Analysis of waveguide-fed thick radiating rectangular windows in a ground plane," IEEE PROCEEDINGS-H, vol. 138, no. 2, 1991.

[13] H. Baudrand; J. Tao; J. Atechian, "Study of Radiating Properties of Open-Ended Rectangular -Waveguides," IEEE Trans. Antennas Propag., vol. 36, no. 8, pp. 1071-1077, 1988.

[14] N. Marcuvitz, Waveguide Handebook. McGraw-Hill, 1951.

[15] D. Pozar, Microwave Engineering Fourth Edition. 2005

[16] X. Wang, O. Abdelatty, and A. Mortazawi, "A Novel Coupling Factor Independent Highly Efficient Resonant Based Wireless Power Transfer," 47th Eur. Microw. Conf. EuMC 2017, pp. 200-203, 2017. 